\title{
Risk factors for severe bleeding events during warfarin treatment: the influence of sex, age, comorbidity and co-medication
}

\author{
Diana M. Rydberg ${ }^{1,2} \cdot$ Marie Linder $^{3} \cdot$ Rickard E. Malmström ${ }^{1,2} \cdot$ Morten Andersen $^{3,4}$
}

Received: 28 November 2019 / Accepted: 5 March 2020 / Published online: 28 March 2020

(C) The Author(s) 2020

\begin{abstract}
Purpose To investigate risk factors for severe bleeding during warfarin treatment, including the influence of sex, age, comorbidity and co-medication on bleeding risk.

Methods Patients initiating warfarin treatment between 2007 and 2011 were identified in the nationwide Swedish Prescribed Drug Register, and diagnoses of severe bleeding were retrieved from the National Patient Register. Hazard ratios (HR) with $95 \%$ confidence intervals (CI) for severe bleeding were estimated using multiple Cox regression adjusting for indications and including covariates age, sex, comorbidities and co-medications. Interactions between sex and other covariates were investigated.

Results The study cohort included 232,624 patients $\geq 18$ years (101,011 women and 131,613 men). The incidence rate of severe bleeding was 37 per 1000 person-years, lower among women than men with an adjusted HR (95\% CI) of 0.84 (0.80-0.88). Incidence of bleeding increased with age, HR $2.88(2.37-3.50)$ comparing age $\geq 80$ to $<40$ years, and comorbidities associated with the highest risk of severe bleeding were prior bleeding, HR 1.85 (1.74-1.97); renal failure, HR 1.82 (1.66-2.00); and alcohol dependency diagnosis, HR 1.79 (1.57-2.05). Other comorbidities significantly associated with bleeding events were hypertension, diabetes, peripheral vascular disease, congestive heart failure, liver failure, stroke/TIA, COPD and cancer.

Conclusion Most of the well-established risk factors were found to be significantly associated with bleeding events in our study. We additionally found that women had a lower incidence of bleeding. Potential biases are selection effects, residual confounding and unmeasured frailty.
\end{abstract}

Keywords Anticoagulants $\cdot$ Warfarin $\cdot$ Women $\cdot$ Men $\cdot$ Adverse drug events $\cdot$ Severe bleeding $\cdot$ Haemorrhage $\cdot$ Sex differences

Electronic supplementary material The online version of this article (https://doi.org/10.1007/s00228-020-02856-6) contains supplementary material, which is available to authorized users.

Diana M. Rydberg

diana.rydberg@ki.se

1 Department of Medicine Solna, Karolinska Institutet, Stockholm, Sweden

2 Clinical Pharmacology, Drug Evaluation Unit, L2:04, Karolinska University Hospital Solna, 17176 Stockholm, Sweden

3 Centre for Pharmacoepidemiology, Department of Medicine Solna, Karolinska Institutet, Stockholm, Sweden

4 Department of Drug Design and Pharmacology, Faculty of Health and Medical Sciences, University of Copenhagen,

Copenhagen, Denmark

\section{Introduction}

There are several known risk factors for bleeding during treatment with oral anticoagulants, such as age, chronic comorbidities, prior bleeding and certain co-medications which are included in the HAS-BLED score [1]. Sex is not included in this risk score, and conflicting results have been found in different populations with several studies showing no difference in bleeding risk between the sexes [2-7], while other studies found a higher risk of bleeding in men [8-11]. To our knowledge, there is a lack of large population-based register studies on sex differences in severe bleeding risks in warfarin-treated patients. Therefore, we performed a study using national health registers with the aim to investigate risk factors for severe bleeding after initiation of warfarin including the influence of sex on the incidence of bleeding events. 


\section{Methods}

\section{Data sources}

As data sources in this study, we used Swedish national health registers covering the entire population. Data were linked using the personal identity number (PIN) that uniquely identifies all citizens in Sweden. For information on dispensed prescription on warfarin and co-medication, we used the Swedish Prescribed Drug Register (PDR), held by the National Board of Health and Welfare, with data on all dispensed prescriptions in Sweden since July 2005 [12], including Anatomical Therapeutic Chemical classification (ATC) codes [13]. The coverage of the PDR is high with $>99.7 \%$ of all prescriptions being recorded with PINs [14]. Diagnoses corresponding to the indications for warfarin treatment, comorbidity and bleeding diagnoses were identified through the Swedish National Patient Register (NPR) [15-18]. The NPR holds information on primary and up to 30 secondary diagnoses from all hospitalizations, nationwide since 1987 and outpatient encounters since 2001. Diagnoses are recorded by the International Classification of Diseases (ICD) system, and the version used in this study is the 10th version (ICD-10), used since 1997. Additionally, the register holds information on surgical procedures performed at hospitals using the Nordic Classification of Surgical Procedures [19]. Information on cancer, including the date of diagnosis, was retrieved from the Swedish Cancer Register [20]. The Cause of Death Register [21] and the Register of the Total Population [22] hold information on individual's sex, dates of birth, death and migration. Register data were de-identified for research use.

\section{Study population and follow-up}

Women and men over 18 years of age with a dispensed warfarin prescription (ATC code B01AA03) in PDR during the study period January 1, 2007, until December 31, 2011, were included in the study cohort. The inclusion period ended before the introduction of non-vitamin $\mathrm{K}$ oral anticoagulants (NOACs). The index date was the first date of a warfarin dispensing during this period. We only included new users, i.e. patients with no vitamin $\mathrm{K}$ antagonist (VKA) use 1 year prior to index date. We excluded subjects not resident in Sweden the year before and included the index date (Fig. 1). All patients in the cohort were followed for the occurrence of bleeding events until a maximum of 12 months after the index date, emigration or death, whichever occurred first (intention-to-treat-like approach).

\section{Indications}

The PDR does not hold information on the indication for drug treatment, and therefore, we as proxies included covariates corresponding to the likely indications of warfarin identified in the NPR through the main and secondary discharge diagnosis, as well as the outpatient visit diagnosis (suppl. Table 1). The indications for warfarin included in the analyses were venous thrombosis (VT), pulmonary embolism (PE), venous thromboembolism (VTE) prophylaxis, peripheral systemic embolism, vascular prosthesis, valvular disease, valvular and non-valvular atrial fibrillation (VAF and NVAF), cardioversion, cardiomyopathy, valvular prosthesis and mitral stenosis. For VAF and NVAF, we used diagnoses occurring up to 10 years before the index date, and for the other indications, we used a time window of 3 months before the index date. In the analysis, a patient could be classified as having several possible indications.

\section{Outcomes}

The primary outcome was the first severe bleeding event leading to hospitalization, identified as a main or secondary diagnosis in the NPR. We used the approach for identification of severe bleeding in health registers validated by Friberg et al. [23]. As secondary outcomes, we investigated severe bleeding categorized by anatomical site [23] (Suppl. Table 2).

\section{Comorbidity and co-medication}

In the analyses, we included covariates representing comorbidities and co-medications. For comorbidities, similar definitions and International Classification of Diseases, 10th revision (ICD-10) codes as in two previous studies $[14,24]$ were used, supplemented with definitions and diagnoses used in the Charlson comorbidity index (CCI) $[25,26]$ (Suppl. Table 1). Hospital admissions and outpatient contacts for comorbidities were identified up to 10 years before the index date, as were recorded in the cancer registry. Because of the lack of information on international normalized ratio (INR), a modified HAS-BLED score $[1,27]$ without INR was used for classifying the risk of severe bleeding (Suppl. Table 3). As co-medication, the covariates we included were low-dose aspirin, other antiplatelet agents, NSAIDs, proton pump inhibitors (PPIs), systemic corticosteroids, antidepressants, selective serotonin reuptake inhibitors (SSRIs), antidiabetics and alcohol dependency drugs dispensed within 1 year before index date (Suppl. Table 4). Female hormone therapy was not included due to the different indications and the very different prevalence of use in women and men. However, we performed a restricted analysis excluding patients treated with female hormones. Drugs assessed as having clinically relevant drug interactions with warfarin, i.e. azole antibiotics, macrolides, quinolones, lipid- 
Fig. 1 Study flow chart

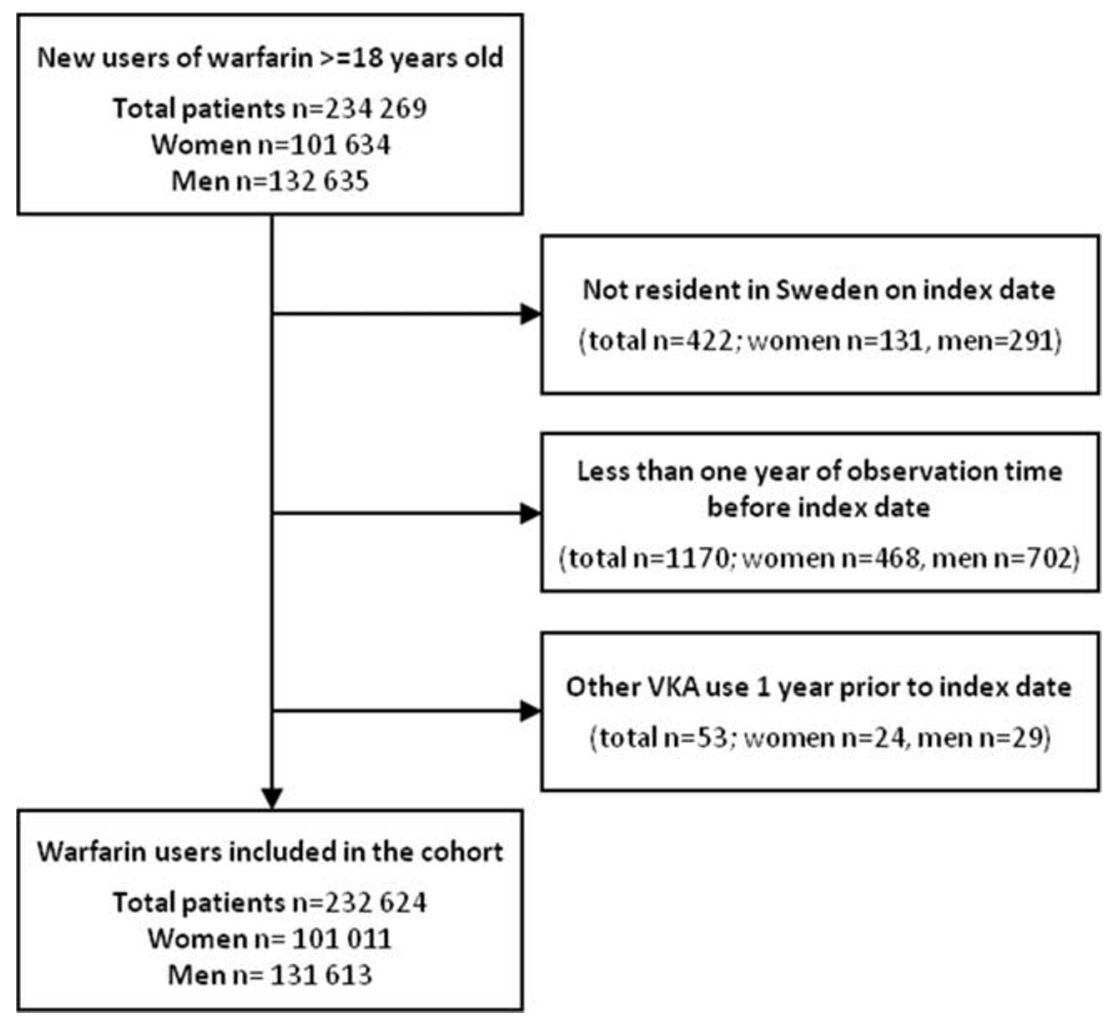

lowering agents, amiodarone and fluorouracil [28], were also included in the analyses (Suppl. Table 4). These consist of drugs where it is either recommended to avoid concomitant treatment with warfarin (D-interactions) or recommended to monitor INR for warfarin dose adjustment (C-interactions) [29].

\section{Ethical approval}

The study was approved by the Regional Ethical Review Board at Karolinska Institutet (Stockholm, Sweden; Dnr 2013/1850-31/1 and 2014/2215-32).

\section{Statistics}

Descriptive statistics are presented as numbers and proportions. Using multiple Cox regression, we estimated hazard ratios (HR) for severe bleeding in models including as covariates sex, age, comorbidities and co-medication. The HRs were presented with a $95 \%$ confidence interval (CI). We finally investigated the effect modification for each covariate by including an interaction term between the covariate and sex in the model. In additional regression models, we adjusted for age as a continuous variable instead of categorical and included co-medications that could lead to drug interactions with warfarin. All analyses were carried out using SAS® software, Version 9.4 (SAS Institute Inc., Cary, NC, USA).

\section{Results}

We included 232,624 patients (101,011 women and 131,613 men) in the cohort. Baseline characteristics of the study population are presented in Table 1. The mean (SD) age was 72.2 years for women and 68.5 years for men, with an excess of persons in the age group $\geq 80$ years among females.

The most common indications for warfarin treatment were atrial fibrillation, venous thromboembolism (VT and PE), followed by valvular diseases. The indications for warfarin treatment differed between women and men, with VT, PE and NVAF being more common in women compared to men. On the other hand, less women than men had valvular disease. The most common comorbidities were cardiovascular diseases, i.e. hypertension, ischemic heart disease, and congestive heart failure, followed by ischemic stroke or TIA. The frequency of comorbidities also differed between the sexes (Table 1) with, e.g. more women with hypertension but more men with diabetes mellitus, myocardial infarction and ischemic heart disease. Women more often had "high" HAS-BLED risk scores. There were also sex differences in co-medication, with more women treated with NSAIDs, PPIs, antidepressants, SSRIs and systemic corticosteroids, compared to men. More men than women were treated with low-dose aspirin, other antiplatelet agents, alcohol dependency drugs and antidiabetics.

The crude incidence rate of severe bleeding was 37 per 1000 person-years, in women 35 and in men 38 per 1000 
Table 1 Warfarin study cohort characteristics

\begin{tabular}{|c|c|c|c|c|}
\hline & $\begin{array}{l}\text { Women } \\
N\end{array}$ & $\%$ & $\begin{array}{l}\text { Men } \\
\mathrm{N}\end{array}$ & $\%$ \\
\hline Total & 101,011 & 100.0 & 131,613 & 100.0 \\
\hline Age, y mean (SD) & $72.2(13.9)$ & & $68.5(12.8)$ & \\
\hline \multicolumn{5}{|l|}{ Age group, y } \\
\hline$<40$ & 4045 & 4.0 & 4012 & 3.0 \\
\hline $40-49$ & 3789 & 3.8 & 7125 & 5.4 \\
\hline $50-59$ & 6435 & 6.4 & 15,695 & 11.9 \\
\hline $60-69$ & 19,165 & 19.0 & 37,172 & 28.2 \\
\hline $70-79$ & 33,169 & 32.8 & 41,571 & 31.6 \\
\hline$\geq 80$ & 34,408 & 34.1 & 26,038 & 19.8 \\
\hline \multicolumn{5}{|l|}{ Indications $\mathrm{s}^{\mathrm{a}}$} \\
\hline Venous thrombosis & 5918 & 5.9 & 5751 & 4.4 \\
\hline Pulmonary embolism & 12,734 & 12.6 & 12,838 & 9.8 \\
\hline VTE prophylaxis & 1899 & 1.9 & 1333 & 1.0 \\
\hline Peripheral systemic embolism & 1144 & 1.1 & 938 & 0.7 \\
\hline Vascular prosthesis & 390 & 0.4 & 1075 & 0.8 \\
\hline Valvular disease & 5544 & 5.5 & 8871 & 6.7 \\
\hline Valvular atrial fibrillation & 4414 & 4.4 & 5932 & 4.5 \\
\hline Non-valvular atrial fibrillation & 39,038 & 38.6 & 47,470 & 36.1 \\
\hline Cardioversion & 734 & 0.7 & 1142 & 0.9 \\
\hline Cardiomyopathy & 790 & 0.8 & 2133 & 1.6 \\
\hline Valve prosthesis & 2676 & 2.6 & 4816 & 3.7 \\
\hline Mitral stenosis & 245 & 0.2 & 95 & 0.1 \\
\hline \multicolumn{5}{|l|}{ Comorbidities/risk factors $^{\mathrm{a}}$} \\
\hline Hypertension $^{\mathrm{c}}$ & 42,475 & 42.0 & 46,092 & 35.0 \\
\hline Diabetes mellitus & 10,964 & 10.9 & 16,237 & 12.3 \\
\hline Myocardial infarction & 10,080 & 10.0 & 19,448 & 14.8 \\
\hline Ischemic heart disease & 17,618 & 17.4 & 30,220 & 23.0 \\
\hline Peripheral vascular disease & 3567 & 3.5 & 6420 & 4.9 \\
\hline Congestive heart failure & 14,448 & 14.3 & 20,348 & 15.5 \\
\hline Renal failure $^{c}$ & 2042 & 2.0 & 3748 & 2.8 \\
\hline Liver failure $^{c}$ & 659 & 0.7 & 1132 & 0.9 \\
\hline Ischemic stroke or TIA ${ }^{\mathrm{c}}$ & 15,355 & 15.2 & 18,038 & 13.7 \\
\hline COPD/emphysema & 5482 & 5.4 & 5867 & 4.5 \\
\hline Cancer (excl. Non-melanoma skin cancer) & 8644 & 8.6 & 11,784 & 9.0 \\
\hline Alcohol dependency diagnosis ${ }^{\mathrm{c}}$ & 745 & 0.7 & 3024 & 2.3 \\
\hline Platelet or coagulation disorder & 1053 & 1.0 & 1012 & 0.8 \\
\hline Prior bleeding ${ }^{\mathrm{c}}$ & 3913 & 3.9 & 4941 & 3.8 \\
\hline \multicolumn{5}{|l|}{ Co-medication ${ }^{\mathrm{b}}$} \\
\hline Low-dose aspirin ${ }^{\mathrm{c}}$ & 42,664 & 42.2 & 59,273 & 45.0 \\
\hline Other antiplatelet agents ${ }^{\mathrm{c}}$ & 6861 & 6.8 & 11,235 & 8.5 \\
\hline NSAIDs $^{\mathrm{c}}$ & 22,645 & 22.4 & 26,197 & 19.9 \\
\hline PPIs & 28,836 & 28.5 & 27,979 & 21.3 \\
\hline Antidepressants & 16,301 & 16.1 & 11,133 & 8.5 \\
\hline Systemic corticosteroids & 15,499 & 15.3 & 14,032 & 10.7 \\
\hline Female hormone therapy and contraceptives & 22,085 & 21.9 & 97 & 0.1 \\
\hline Alcohol dependency drugs ${ }^{\mathrm{c}}$ & 144 & 0.1 & 653 & 0.5 \\
\hline Antidiabetics & 11,151 & 11.0 & 17,920 & 13.6 \\
\hline \multicolumn{5}{|l|}{ Interactions $\mathrm{s}^{\mathrm{b}}$} \\
\hline D interactions & 2935 & 2.9 & 2701 & 2.1 \\
\hline Fluconazole & 2031 & 2.0 & 879 & 0.7 \\
\hline Sulfamethoxazole & 1012 & 1.0 & 1947 & 1.5 \\
\hline $\mathrm{C}$ interactions & 42,606 & 42.2 & 53,605 & 40.7 \\
\hline HAS-BLED risk score, mean (SD) & $2.0(1.2)$ & & $1.8(1.2)$ & \\
\hline \multicolumn{5}{|l|}{ HAS-BLED risk score } \\
\hline Low risk (0-1 points) & 36,362 & 36.0 & 55,836 & 42.4 \\
\hline Intermediate risk ( 2 points) & 30,318 & 30.0 & 37,937 & 28.8 \\
\hline High risk ( $\geq 3$ points) & 34,331 & 34.0 & 37,840 & 28.8 \\
\hline
\end{tabular}

${ }^{a}$ See supplementary Table 1 for definitions

${ }^{\mathrm{b}}$ See supplementary Table 4 for definitions

${ }^{\mathrm{c}}$ Included in the modified HAS-BLED score 
person-years. In the analyses of overall risk of severe bleeding, we found a significantly lower risk in women compared to men with a crude HR $(95 \% \mathrm{CI})$ of $0.94(0.90-0.98)$ that was further reduced $0.84(0.80-0.88)$ after adjustment for age, indications, comorbidities and co-medication (Table 2).

Table 2 shows the association of covariates with severe bleeding risk. Indications for warfarin associated with a higher risk of severe bleeding were valvular disease with a HR of 1.53 (1.35-1.74), venous thrombosis 1.32 (1.20-1.44), peripheral systemic embolism $1.40(1.17-1.67)$ and pulmonary embolism 1.14 (1.07-1.23). Comorbidities associated with the highest risk of severe bleeding were prior bleeding 1.85 (1.74-1.97), renal failure 1.82 (1.66-2.00) and alcohol dependency diagnosis 1.79 (1.57-2.05). Co-medications associated with a higher risk of severe bleeding were "other antiplatelet agents", NSAIDs, PPIs, antidepressants, SSRIs, systemic corticosteroids and alcohol dependency drugs with HR (95\% CI) 1.49 (1.11-1.99).

Among drugs with a known interaction with warfarin, only sulfamethoxazole, ciprofloxacin and simvastatin significantly influenced bleeding risk in an adjusted analysis (data not shown). Including these covariates in the analysis did not change our estimates.

In the analysis of site-specific severe bleedings (Suppl Table 5), women had a lower adjusted risk of CNS bleeding and urogenital bleeding than men, while there was no difference in the risk of GI bleeding and other bleedings.

In the analyses of effect modification (Suppl Table 6), women in the age groups 40-49 and 50-59 had a higher risk of severe bleeding than men. The lower severe bleeding risk in women was independent of indications, HAS-BLED score and comorbidities except renal failure, COPD and prior bleeding. For patients with renal failure, the risk in women exceeded the risk in men. For co-medications, only low-dose aspirin differed from the general pattern with an even more pronounced lower risk of severe bleeding in women (Suppl Table 6).

Adjustments for age as a continuous variable did not change the overall estimates. Neither did the exclusion of patients receiving female hormone therapy and contraceptives lead to important changes in HRs.

\section{Discussion}

In our study, we found that the risk of severe bleeding was significantly associated with the majority of the risk factors included in the HAS-BLED score: age, hypertension, renal and liver failure, ischemic stroke or TIA, prior bleeding, alcohol dependency and co-medication with antiplatelet agents and NSAIDs. We additionally found a higher bleeding risk associated with other factors: diabetes, peripheral vascular disease, congestive heart failure, COPD and cancer.
Furthermore, we found an overall lower risk of severe bleeding during warfarin treatment in women compared to men, even more pronounced after adjustment for other factors.

The HAS-BLED risk score has been compared to other risk scores which include additional or other risk factors, such as diabetes and cancer [30-32]. Cancer patients with venous thrombosis are more likely to develop major bleeding during anticoagulant treatment than those without malignancy [33]. Diabetes and congestive heart failure have not previously been associated with a higher bleeding risk during treatment with anticoagulants $[34,35]$. A higher bleeding risk during warfarin treatment after 2 years was seen in patients with peripheral artery disease (PAD) [36]. An association between a higher risk of GI-bleeding in patients with COPD has also previously been found [37, 38].

The finding of a lower risk of severe bleeding during warfarin treatment in women is in line with two other studies. A study with elderly patients with AF or VT on VKA treatment with a higher rate of bleeding events in men [10] and a Swedish cohort study on warfarin-naïvepatients showing male sex as an independent risk factor of severe bleeding [9]. The lower risk of CNS bleeding in women found in our study was also in line with another Swedish study on warfarin-treated AF patients [8]. Furthermore, despite the on average lower risk and consistency across analyses stratified on most risk factors, our results showed that in the age groups of 40-49 and 50-59 and in patients with renal failure, women may have a higher risk of severe bleeding than men.

In a study on older patients with VKAs [39], frequent use of NSAIDs or selective COX-2-inhibitors was a strong risk factor for upper gastrointestinal haemorrhage. In our study, however, co-medication with NSAIDs only slightly increased bleeding risk (Table 2). This could be due to the physicians selecting low-risk patient for combination therapy. Concomitant use of aspirin or other antiplatelet drugs in patients with anticoagulants is a known risk factor for bleeding complications $[40,41]$ with an especially high risk in elderly patients $[42,43]$. The risk of low-dose aspirin disappeared in the adjusted analysis (Table 2), which may be explained by a similar selection effect or correlation of aspirin use with other strong risk factors.

Our findings of a lower risk of severe bleeding in women compared to men should be viewed in the light of the risk benefit balance for stroke prevention in women with AF on warfarin, where the differences in the epidemiology of stroke among women and men must be acknowledged. In Sweden, men are more frequently prescribed antithrombotic treatment compared to women [44], and the national US registry data show that women were significantly less likely to use any oral anticoagulant for $\mathrm{AF}$ overall and at all levels of $\mathrm{CHA}_{2} \mathrm{DS}_{2}-$ VASc score compared to men [45]. Data from a global register study on patients with newly diagnosed NVAF show that the use of anticoagulant therapy for stroke prevention is similar for women and men (approximately 60\%), with underuse of 
Table 2 Hazard ratios (HR) for severe bleeding: associations with sex, age groups, indications, comorbidities, risk factors for bleeding and co-medication. Cox regression, crude and adjusted for all covariates

\begin{tabular}{|c|c|c|}
\hline & $\begin{array}{l}\text { Crude } \\
\text { HR }(95 \% \mathrm{CI})\end{array}$ & $\begin{array}{l}\text { Adjusted } \\
\text { HR }(95 \% \text { CI) }\end{array}$ \\
\hline Women vs. men & $0.94(0.90-0.98)$ & $0.85(0.81-0.89)$ \\
\hline \multicolumn{3}{|l|}{ Age group, y } \\
\hline$<40$ & 1 (reference) & 1 (reference) \\
\hline $40-49$ & $1.23(0.97-1.55)$ & $1.13(0.89-1.42)$ \\
\hline $50-59$ & $1.66(1.35-2.04)$ & $1.41(1.15-1.74)$ \\
\hline $60-69$ & $2.06(1.70-2.50)$ & $1.67(1.38-2.03)$ \\
\hline $70-79$ & $2.80(2.32-3.38)$ & $2.19(1.81-2.66)$ \\
\hline$\geq 80$ & $3.80(3.15-4.59)$ & $2.88(2.37-3.50)$ \\
\hline \multicolumn{3}{|l|}{ Indications $^{\mathrm{a}}$} \\
\hline Venous thrombosis & $1.33(1.22-1.46)$ & $1.32(1.20-1.44)$ \\
\hline Pulmonary embolism & $1.12(1.04-1.19)$ & $1.14(1.07-1.23)$ \\
\hline VTE prophylaxis & $1.11(0.93-1.32)$ & $1.05(0.88-1.25)$ \\
\hline Peripheral systemic embolism & $1.81(1.52-2.16)$ & $1.40(1.17-1.67)$ \\
\hline Valvular disease & $1.60(1.48-1.72)$ & $1.53(1.35-1.74)$ \\
\hline Valvular atrial fibrillation & $1.64(1.50-1.79)$ & $0.96(0.85-1.07)$ \\
\hline Non-valvular atrial fibrillation & $1.18(1.13-1.24)$ & $1.03(0.98-1.08)$ \\
\hline Cardioversion & $0.90(0.70-1.16)$ & $0.86(0.67-1.12)$ \\
\hline Cardiomyopathy & $1.02(0.84-1.23)$ & $0.94(0.78-1.15)$ \\
\hline Valve prosthesis & $1.42(1.27-1.57)$ & $0.90(0.78-1.04)$ \\
\hline Mitral stenosis & $2.12(1.42-3.16)$ & $1.33(0.88-2.00)$ \\
\hline \multicolumn{3}{|l|}{ Comorbidities/risk factors ${ }^{\mathrm{a}}$} \\
\hline Hypertension $^{\mathrm{b}}$ & $1.73(1.66-1.81)$ & $1.22(1.16-1.28)$ \\
\hline Diabetes mellitus & $1.68(1.59-1.78)$ & $1.16(1.04-1.28)$ \\
\hline Myocardial infarction & $1.66(1.57-1.75)$ & $1.07(0.99-1.17)$ \\
\hline Ischemic heart disease & $1.63(1.55-1.71)$ & $1.01(0.93-1.09)$ \\
\hline Peripheral vascular disease & $1.93(1.78-2.09)$ & $1.28(1.17-1.39)$ \\
\hline Congestive heart failure & $1.75(1.66-1.84)$ & $1.19(1.12-1.26)$ \\
\hline Renal failure $^{\mathrm{b}}$ & $3.13(2.87-3.41)$ & $1.82(1.66-2.00)$ \\
\hline Liver failure $^{\mathrm{b}}$ & $2.07(1.73-2.46)$ & $1.43(1.19-1.72)$ \\
\hline Ischemic stroke or TIA ${ }^{\mathrm{b}}$ & $1.40(1.33-1.48)$ & $1.07(1.00-1.13)$ \\
\hline Chronic obstructive pulmonary disease/emphysema & $1.79(1.66-1.94)$ & $1.18(1.09-1.29)$ \\
\hline Cancer (excl. non-melanoma skin cancer) & $1.68(1.57-1.79)$ & $1.33(1.24-1.42)$ \\
\hline Alcohol dependency diagnosis ${ }^{\mathrm{b}}$ & $2.04(1.80-2.31)$ & $1.79(1.57-2.05)$ \\
\hline Platelet or coagulation disorder & $1.43(1.18-1.74)$ & $1.13(0.92-1.37)$ \\
\hline Prior bleeding ${ }^{\mathrm{b}}$ & $2.63(2.48-2.79)$ & $1.85(1.74-1.97)$ \\
\hline \multicolumn{3}{|l|}{ Co-medication ${ }^{\mathrm{a}}$} \\
\hline Low-dose aspirin ${ }^{\mathrm{b}}$ & $1.34(1.28-1.39)$ & $0.95(0.91-1.00)$ \\
\hline Other antiplatelet agents ${ }^{\mathrm{b}}$ & $1.60(1.49-1.71)$ & $1.17(1.09-1.26)$ \\
\hline NSAIDs $^{b}$ & $1.01(0.96-1.06)$ & $1.06(1.00-1.12)$ \\
\hline PPIs & $1.46(1.40-1.53)$ & $1.09(1.04-1.15)$ \\
\hline Antidepressants & $1.43(1.34-1.51)$ & $1.23(1.16-1.31)$ \\
\hline Systemic corticosteroids & $1.47(1.39-1.56)$ & $1.20(1.13-1.27)$ \\
\hline Alcohol dependency drugs ${ }^{\mathrm{b}}$ & $1.81(1.37-2.39)$ & $1.49(1.11-1.99)$ \\
\hline Antidiabetics & $1.47(1.39-1.56)$ & $1.06(0.96-1.17)$ \\
\hline
\end{tabular}

\footnotetext{
${ }^{\text {a }}$ Yes vs no

${ }^{\mathrm{b}}$ Included in the modified HAS-BLED score
} 
anticoagulation therapy in high-risk patients reported for both sexes. At the same time, an overuse of anticoagulation was also reported in individuals with a low risk of stroke [46]. Meta-analyses on sex differences in stroke in AF patients found higher risk of stroke in women [6,47], and in patients with ischemic stroke and ICH, there were fewer women with good post-stroke functioning compared to men [48], and a possible higher net clinical benefit of VKA treatment in women was suggested in a study showing a slightly higher rate of stroke in women [7]. Our results could partially reflect the fact that the physicians avoid anticoagulation treatment in women with a high bleeding risk to a higher extent than in high-risk men, especially in the older age groups.

\section{Strengths and limitations}

The use of data from population-based healthcare registers with full coverage implies that we avoided recall bias and that there is no selection bias related to the study population. By using the validated bleeding diagnoses by Friberg et al. [23], we ensured the correct identification of the outcome.

With the introduction of the NOACs, prescription patterns changed, and switches between the different antithrombotic substances became common [49]. We therefore chose a period before the introduction of NOACs to avoid the complexity with several different antithrombotic substances and indications to consider and a possible selection bias related to the choice of therapy (channelling).

The PDR lacks information on indications, and therefore diagnoses from the NPR corresponding to the indication for warfarin treatment were used as a proxy. Receiving a certain diagnosis depends on patient or physician attitudes and careseeking behaviour, which potentially could lead to sex differences in diagnoses recorded in the registers. Women have more contact with the healthcare system throughout their lifespan [50-52], which gives them an extra opportunity for disease detection and perhaps more diagnoses/comorbidities. We thus cannot exclude that differential misclassification of diagnoses in women and men could have affected our results. Furthermore, some NSAIDs are available over-the-counter (OTC). Therefore, NSAID use is likely underestimated in our analysis which is based on dispensed prescriptions.

Information on dosage and dates of treatment discontinuation were not available. We performed an intention-to-treat analysis, with the assumption that the warfarin treatment was ongoing throughout the 12-month follow-up period. A gender difference in adherence to warfarin treatment could have contributed to the sex difference in severe bleeding. However, a Swedish nationwide observational study showed no difference between women and men for persistence to warfarin treatment in patients prescribed secondary preventive drugs after stroke [53]. Similarly, differential adherence or persistence could lead to biased effects of other risk factors.
Our results may be confounded by patient frailty. Age and several of the chronic comorbidities we include in the analysis are likely to be associated with frailty, but clinical assessments of frailty were not available. It is noted that the association of bleeding risk with age is only moderately attenuated after adjustment, which could be ascribed to confounding by unmeasured frailty.

We did not have access to diagnoses from primary care, and therefore, we do not have complete information on comorbidities. Hypertension was adjusted for in our analysis, but no data on blood pressure control were available. In a study with data from the Swedish Primary Care Cardiovascular Database, fewer women than men reached target blood pressure [54], but among US adults, women had generally higher hypertension control [55]. Sex differences in hypertension control could potentially contribute to differences in the risk of severe bleeding.

Finally, it is a limitation that our study lacked data on INR and time in therapeutic range (TTR). The adjustment for diagnoses representing the indication for treatment may in part control for systematic differences in INR level and monitoring intensity. For example, valvular disease was associated with a higher bleeding risk. In a study investigating adverse outcomes in women and men with AF taking warfarin in the AMADEUS trial, TTR but not female sex was an independent predictor for combined cardiovascular death and stroke/ systemic embolism and clinically relevant bleeding events [11]. Studies based on data from the Swedish national quality registry for $\mathrm{AF}$ and anticoagulation have shown that there was no significant difference in TTR between women and men $[56,57]$. However, these studies did not assess the direction of the INR deviation from the therapeutic range that could result in either an increased risk of bleeding or an increased risk of thromboembolic events. In a study on epidemiology of subtherapeutic anticoagulation in the USA, women treated for venous thromboembolism were particularly likely to experience low INR [58]. Thus, a lower treatment intensity in women could contribute to a lower bleeding risk.

\section{Conclusion}

In this population-based cohort study in patients on warfarin, the majority of risk factors included in the HAS-BLED score could be confirmed to be significantly associated with a higher risk of bleeding. We also identified an association with several other comorbidities, i.e. diabetes, peripheral vascular disease, congestive heart failure, COPD and cancer. Women had a lower overall incidence of severe bleeding even after adjusting for age, comorbidity and co-medication. The apparent effect of sex was, however, relatively small compared with the effects of other risk factors. 
Our findings could partially be explained by selection effects and confounding due to the limitations of our data, including unmeasured confounders, notably treatment intensity and patient frailty.

The individualized dosing may be a key factor, and therefore, exploring risk factors including sex differences in severe bleeding in patients on NOACs with standardized dosing becomes highly relevant. Future studies should also investigate factors not present in healthcare registers that may influence treatment choice and intensity of treatment. For VKA, including information on INR is highly relevant.

Acknowledgements Open access funding provided by Karolinska Institute.

Authors' contributions DMR: Responsible for study design, planning of statistical analyses, interpretation and presentation of results, writing and revising the manuscript

ML: Statistical advice and supervision on study design and statistical analyses, interpretation and presentation of results, reviewing the manuscript

REM: Responsible for study design, interpretation of results, reviewing the manuscript

MA: Responsible for study design, planning and conducting of statistical analyses, interpretation and presentation of results, reviewing the manuscript

Funding information The study was funded by the Swedish Association of Local Authorities and Regions (SALAR) within the Sustainable Equality Project (HÅJ), No. SKL 08/2254, Stockholm County Council, the Centre for Gender Medicine (Erica Lederhausen Foundation), Karolinska Institutet and the Drug Therapeutics Committee of Stockholm County.

\section{Compliance with ethical standards}

Conflict of interest MA reports grants from AstraZeneca, Pfizer, $\mathrm{H}$. Lundbeck and Mertz, Novartis, Janssen and Novo Nordisk Foundation (NNF15SA0018404), outside the submitted work; all grants received by the institutions of his employment; and personal fees for organizing pharmacoepidemiology courses and teaching at Atrium, the Danish Association for the Pharmaceutical Industry. ML is employed at the Centre for Pharmacoepidemiology, which receive grants from pharmaceutical companies, including Takeda, regulatory authorities and contract research organizations for performance of drug safety and drug utilization studies. DMR and REM have no conflicts of interest.

Ethical approval The study was approved by the Regional Ethical Review Board at Karolinska Institutet (Stockholm, Sweden; Dnr 2013/1850-31/1 and 2014/2215-32).

Open Access This article is licensed under a Creative Commons Attribution 4.0 International License, which permits use, sharing, adaptation, distribution and reproduction in any medium or format, as long as you give appropriate credit to the original author(s) and the source, provide a link to the Creative Commons licence, and indicate if changes were made. The images or other third party material in this article are included in the article's Creative Commons licence, unless indicated otherwise in a credit line to the material. If material is not included in the article's Creative Commons licence and your intended use is not permitted by statutory regulation or exceeds the permitted use, you will need to obtain permission directly from the copyright holder. To view a copy of this licence, visit http://creativecommons.org/licenses/by/4.0/.

\section{References}

1. Pisters R, Lane DA, Nieuwlaat R, de Vos CB, Crijns HJ, Lip GY (2010) A novel user-friendly score (HAS-BLED) to assess 1-year risk of major bleeding in patients with atrial fibrillation: the euro heart survey. Chest 138(5):1093-1100. https://doi.org/10.1378/ chest.10-0134

2. Dagres N, Nieuwlaat R, Vardas PE, Andresen D, Levy S, Cobbe S, Kremastinos DT, Breithardt G, Cokkinos DV, Crijns HJ (2007) Gender-related differences in presentation, treatment, and outcome of patients with atrial fibrillation in Europe: a report from the euro heart survey on atrial fibrillation. J Am Coll Cardiol 49(5):572-577. https://doi.org/10.1016/j.jacc.2006.10.047

3. Fang MC, Singer DE, Chang Y, Hylek EM, Henault LE, Jensvold NG, Go AS (2005) Gender differences in the risk of ischemic stroke and peripheral embolism in atrial fibrillation: the anticoagulation and risk factors in atrial fibrillation (ATRIA) study. Circulation 112(12):1687-1691. https://doi.org/10.1161/ CIRCULATIONAHA.105.553438

4. Gomberg-Maitland M, Wenger NK, Feyzi J, Lengyel M, Volgman AS, Petersen P, Frison L, Halperin JL (2006) Anticoagulation in women with non-valvular atrial fibrillation in the stroke prevention using an oral thrombin inhibitor (SPORTIF) trials. Eur Heart J 27(16):1947-1953. https://doi.org/10.1093/eurheartj/ehl103

5. Palareti G, Leali N, Coccheri S, Poggi M, Manotti C, D'Angelo A, Pengo V, Erba N, Moia M, Ciavarella N, Devoto G, Berrettini M, Musolesi S (1996) Bleeding complications of oral anticoagulant treatment: an inception-cohort, prospective collaborative study (ISCOAT). Italian study on complications of oral anticoagulant therapy. Lancet 348(9025):423-428

6. Pancholy SB, Sharma PS, Pancholy DS, Patel TM, Callans DJ, Marchlinski FE (2014) Meta-analysis of gender differences in residual stroke risk and major bleeding in patients with nonvalvular atrial fibrillation treated with oral anticoagulants. Am J Cardiol 113(3):485-490. https://doi.org/10.1016/j.amjcard.2013.10.035

7. Poli D, Antonucci E, Testa S, Ageno W, Palareti G (2013) Gender differences of bleeding and stroke risk in very old atrial fibrillation patients on VKA treatment: results of the EPICA study on the behalf of FCSA (Italian Federation of Anticoagulation Clinics). Thromb Res 131(1):12-16. https://doi.org/10.1016/j.thromres. 2012.10.009

8. Bjorck F, Renlund H, Lip GY, Wester P, Svensson PJ, Sjalander A (2016) Outcomes in a warfarin-treated population with atrial fibrillation. JAMA Cardiol 1(2):172-180. https://doi.org/10.1001/ jamacardio.2016.0199

9. Lindh JD, Holm L, Dahl ML, Alfredsson L, Rane A (2008) Incidence and predictors of severe bleeding during warfarin treatment. J Thromb Thrombolysis 25(2):151-159. https://doi.org/10. 1007/s11239-007-0048-2

10. Poli D, Antonucci E, Testa S, Tosetto A, Ageno W, Palareti G (2011) Bleeding risk in very old patients on vitamin K antagonist treatment: results of a prospective collaborative study on elderly patients followed by Italian centres for anticoagulation. Circulation 124(7):824-829. https://doi.org/10.1161/ CIRCULATIONAHA.110.007864

11. Senoo K, Lip GY (2016) Female sex, time in therapeutic range, and clinical outcomes in atrial fibrillation patients taking warfarin. Stroke 47(6):1665-1668. https://doi.org/10.1161/STROKEAHA. 116.013173 
12. Wettermark B, Hammar N, Fored CM, Leimanis A, Otterblad Olausson P, Bergman U, Persson I, Sundstrom A, Westerholm B, Rosen M (2007) The new Swedish prescribed drug registeropportunities for pharmacoepidemiological research and experience from the first six months. Pharmacoepidemiol Drug Saf 16(7):726-735. https://doi.org/10.1002/pds.1294

13. WHO (2019) ATC Index with DDDs. https://www.whocc.no/atc ddd_index_and_guidelines/atc_ddd_index/. Accessed 14 August 2019

14. Forslund T, Wettermark B, Wandell P, von Euler M, Hasselstrom J, Hjemdahl P (2014) Risks for stroke and bleeding with warfarin or aspirin treatment in patients with atrial fibrillation at different CHA(2)DS(2)VASc scores: experience from the Stockholm region. Eur J Clin Pharmacol 70(12):1477-1485. https://doi.org/10.1007/ s00228-014-1739-1

15. Ingelsson E, Arnlov J, Sundstrom J, Lind L (2005) The validity of a diagnosis of heart failure in a hospital discharge register. Eur J Heart Fail 7(5):787-791. https://doi.org/10.1016/j.ejheart.2004.12.007

16. Ludvigsson JF, Andersson E, Ekbom A, Feychting M, Kim JL, Reuterwall C, Heurgren M, Olausson PO (2011) External review and validation of the Swedish national inpatient register. BMC Public Health 11:450. https://doi.org/10.1186/1471-2458-11-450

17. Ragnarson Tennvall G, Apelqvist J, Eneroth M (2000) The inpatient care of patients with diabetes mellitus and foot ulcers. A validation study of the correspondence between medical records and the Swedish inpatient registry with the consequences for cost estimations. J Intern Med 248(5):397-405

18. Smith JG, Platonov PG, Hedblad B, Engstrom G, Melander O (2010) Atrial fibrillation in the Malmo diet and cancer study: a study of occurrence, risk factors and diagnostic validity. Eur J Epidemiol 25(2):95-102. https://doi.org/10.1007/s10654-0099404-1

19. NOMESCO (2010) NOMESCO Classification of Surgical Procedures (NCSP), version 1.15. http://norden.diva-portal.org/ smash/get/diva2:970547/FULLTEXT01.pdf. Accessed 14 August 2019

20. Socialstyrelsen The Swedish Cancer Register. https://www. socialstyrelsen.se/en/statistics-and-data/registers/alla-register/ swedish-cancer-register/. Accessed 15 August 2019

21. Socialstyrelsen Dödsorsaksregistret. https://www.socialstyrelsen. se/register/dodsorsaksregistret. Accessed 15 August 2019

22. Skatteverket Folkbokföringsdatabasen. https://www.skatteverket.se/ privat/folkbokforing/attvarafolkbokford/folkbokforingsdatabasen.4. 3810a01c150939e893fl6fe2.html. Accessed 15 August 2019

23. Friberg L, Skeppholm M (2016) Usefulness of health registers for detection of bleeding events in outcome studies. Thromb Haemost 116(6):1131-1139. https://doi.org/10.1160/TH16-05-0400

24. Friberg L, Rosenqvist M, Lip GY (2012) Evaluation of risk stratification schemes for ischaemic stroke and bleeding in 182678 patients with atrial fibrillation: the Swedish atrial fibrillation cohort study. Eur Heart J 33(12):1500-1510. https://doi.org/10.1093/ eurheartj/ehr488

25. Charlson ME, Pompei P, Ales KL, MacKenzie CR (1987) A new method of classifying prognostic comorbidity in longitudinal studies: development and validation. J Chronic Dis 40(5):373-383

26. Quan H, Sundararajan V, Halfon P, Fong A, Burnand B, Luthi JC, Saunders LD, Beck CA, Feasby TE, Ghali WA (2005) Coding algorithms for defining comorbidities in ICD-9-CM and ICD-10 administrative data. Med Care 43(11):1130-1139

27. Lip GY, Lin HJ, Hsu HC, Su TC, Chen MF, Lee YT, Chien KL (2013) Comparative assessment of the HAS-BLED score with other published bleeding risk scoring schemes, for intracranial haemorrhage risk in a non-atrial fibrillation population: the Chin-Shan community cohort study. Int J Cardiol 168(3):1832-1836. https:// doi.org/10.1016/j.ijcard.2012.12.076
28. Holbrook AM, Pereira JA, Labiris R, McDonald H, Douketis JD, Crowther M, Wells PS (2005) Systematic overview of warfarin and its drug and food interactions. Arch Intern Med 165(10):10951106. https://doi.org/10.1001/archinte.165.10.1095

29. Region-Stockholm Janusmed interaktioner. http://janusmed.sll.se/ about/ominteraktioner/. Accessed 15 August 2019

30. Donze J, Rodondi N, Waeber G, Monney P, Cornuz J, Aujesky D (2012) Scores to predict major bleeding risk during oral anticoagulation therapy: a prospective validation study. Am J Med 125(11):1095-1102. https://doi.org/10.1016/j.amjmed.2012.04. 005

31. Lane DA, Lip GY (2012) Use of the CHA(2)DS(2)-VASc and HAS-BLED scores to aid decision making for thromboprophylaxis in nonvalvular atrial fibrillation. Circulation 126(7):860-865. https://doi.org/10.1161/CIRCULATIONAHA.111.060061

32. Olesen JB, Lip GY, Hansen PR, Lindhardsen J, Ahlehoff O, Andersson C, Weeke P, Hansen ML, Gislason GH, Torp-Pedersen C (2011) Bleeding risk in 'real world' patients with atrial fibrillation: comparison of two established bleeding prediction schemes in a nationwide cohort. J Thromb Haemost 9(8):1460-1467. https:// doi.org/10.1111/j.1538-7836.2011.04378.x

33. Prandoni P, Lensing AW, Piccioli A, Bernardi E, Simioni P, Girolami B, Marchiori A, Sabbion P, Prins MH, Noventa F, Girolami A (2002) Recurrent venous thromboembolism and bleeding complications during anticoagulant treatment in patients with cancer and venous thrombosis. Blood 100(10):3484-3488. https:// doi.org/10.1182/blood-2002-01-0108

34. Fang MC, Go AS, Chang Y, Borowsky LH, Pomernacki NK, Udaltsova N, Singer DE (2011) A new risk scheme to predict warfarin-associated hemorrhage: the ATRIA (anticoagulation and risk factors in atrial fibrillation) study. J Am Coll Cardiol 58(4): 395-401. https://doi.org/10.1016/j.jacc.2011.03.031

35. Held C, Hylek EM, Alexander JH, Hanna M, Lopes RD, Wojdyla DM, Thomas L, Al-Khalidi H, Alings M, Xavier D, Ansell J, Goto S, Ruzyllo W, Rosenqvist M, Verheugt FW, Zhu J, Granger CB, Wallentin L (2015) Clinical outcomes and management associated with major bleeding in patients with atrial fibrillation treated with apixaban or warfarin: insights from the ARISTOTLE trial. Eur Heart J 36(20):1264-1272. https://doi.org/10.1093/eurheartj/ ehu463

36. Hu PT, Lopes RD, Stevens SR, Wallentin L, Thomas L, Alexander JH, Hanna M, Lewis BS, Verheugt FW, Granger CB, Jones WS (2017) Efficacy and safety of apixaban compared with warfarin in patients with atrial fibrillation and peripheral artery disease: insights from the ARISTOTLE trial. J Am Heart Assoc 6(1). https://doi.org/ 10.1161/JAHA.116.004699

37. Sherwood MW, Nessel CC, Hellkamp AS, Mahaffey KW, Piccini JP, Suh EY, Becker RC, Singer DE, Halperin JL, Hankey GJ, Berkowitz SD, Fox KAA, Patel MR (2015) Gastrointestinal bleeding in patients with atrial fibrillation treated with rivaroxaban or warfarin: ROCKET AF trial. J Am Coll Cardiol 66(21):22712281. https://doi.org/10.1016/j.jacc.2015.09.024

38. Shimomura A, Nagata N, Shimbo T, Sakurai T, Moriyasu S, Okubo H, Watanabe K, Yokoi C, Akiyama J, Uemura N (2018) New predictive model for acute gastrointestinal bleeding in patients taking oral anticoagulants: a cohort study. J Gastroenterol Hepatol 33(1): 164-171. https://doi.org/10.1111/jgh.13830

39. Battistella M, Mamdami MM, Juurlink DN, Rabeneck L, Laupacis A (2005) Risk of upper gastrointestinal hemorrhage in warfarin users treated with nonselective NSAIDs or COX-2 inhibitors. Arch Intern Med 165(2):189-192. https://doi.org/10.1001/ archinte.165.2.189

40. Dentali F, Douketis JD, Lim W, Crowther M (2007) Combined aspirin-oral anticoagulant therapy compared with oral anticoagulant therapy alone among patients at risk for cardiovascular disease: a 
meta-analysis of randomized trials. Arch Intern Med 167(2):117124. https://doi.org/10.1001/archinte.167.2.117

41. Shireman TI, Howard PA, Kresowik TF, Ellerbeck EF (2004) Combined anticoagulant-antiplatelet use and major bleeding events in elderly atrial fibrillation patients. Stroke 35(10):2362-2367. https://doi.org/10.1161/01.STR.0000141933.75462.c2

42. Beyth RJ, Landefeld CS (1995) Anticoagulants in older patients. A safety perspective. Drugs Aging 6(1):45-54

43. Palareti G, Hirsh J, Legnani C, Manotti C, D'Angelo A, Pengo V, Moia M, Guazzaloca G, Musolesi S, Coccheri S (2000) Oral anticoagulation treatment in the elderly: a nested, prospective, case-control study. Arch Intern Med 160(4):470-478

44. Loikas D, Wettermark B, von Euler M, Bergman U, SchenckGustafsson K (2013) Differences in drug utilisation between men and women: a cross-sectional analysis of all dispensed drugs in Sweden. BMJ Open 3(5). https://doi.org/10.1136/bmjopen-2012002378

45. Thompson LE, Maddox TM, Lei L, Grunwald GK, Bradley SM, Peterson PN, Masoudi FA, Turchin A, Song Y, Doros G, Davis MB, Daugherty SL (2017) Sex differences in the use of Oral anticoagulants for atrial fibrillation: a report from the National Cardiovascular Data Registry (NCDR((R))) PINNACLE registry. J Am Heart Assoc 6(7). https://doi.org/10.1161/JAHA.117.005801

46. Lip GY, Rushton-Smith SK, Goldhaber SZ, Fitzmaurice DA, Mantovani LG, Goto S, Haas S, Bassand JP, Camm AJ, Ambrosio G, Jansky P, Al Mahmeed W, Oh S, van Eickels M, Raatikainen P, Steffel J, Oto A, Kayani G, Accetta G, Kakkar AK, Investigators G-A (2015) Does sex affect anticoagulant use for stroke prevention in nonvalvular atrial fibrillation? The prospective global anticoagulant registry in the FIELD-atrial fibrillation. Circ Cardiovasc Qual Outcomes 8(2 Suppl 1):S12-S20. https:// doi.org/10.1161/CIRCOUTCOMES.114.001556

47. Marzona I, Proietti M, Farcomeni A, Romiti GF, Romanazzi I, Raparelli V, Basili S, Lip GYH, Nobili A, Roncaglioni MC (2018) Sex differences in stroke and major adverse clinical events in patients with atrial fibrillation: a systematic review and metaanalysis of 993,600 patients. Int J Cardiol 269:182-191. https:// doi.org/10.1016/j.ijcard.2018.07.044

48. Willers C, Lekander I, Ekstrand E, Lilja M, Pessah-Rasmussen H, Sunnerhagen KS, von Euler M (2018) Sex as predictor for achieved health outcomes and received care in ischemic stroke and intracerebral hemorrhage: a register-based study. Biol Sex Differ 9(1):11. https://doi.org/10.1186/s13293-018-0170-1

49. Komen J, Forslund T, Hjemdahl P, Andersen M, Wettermark B (2017) Effects of policy interventions on the introduction of novel oral anticoagulants in Stockholm: an interrupted time series analysis. Br J Clin Pharmacol 83(3):642-652. https://doi.org/10.1111/ bcp. 13150

50. Brooks PM (2006) The burden of musculoskeletal disease-a global perspective. Clin Rheumatol 25(6):778-781. https://doi.org/10. 1007/s10067-006-0240-3

51. Pinkhasov RM, Wong J, Kashanian J, Lee M, Samadi DB, Pinkhasov MM, Shabsigh R (2010) Are men shortchanged on health? Perspective on health care utilization and health risk behavior in men and women in the United States. Int J Clin Pract 64(4): 475-487. https://doi.org/10.1111/j.1742-1241.2009.02290.x

52. Vaidya V, Partha G, Karmakar M (2012) Gender differences in utilization of preventive care services in the United States. J Women's Health (Larchmt) 21(2):140-145. https://doi.org/10. 1089/jwh.2011.2876

53. Sjolander M, Eriksson M, Glader EL (2012) Few sex differences in the use of drugs for secondary prevention after stroke: a nationwide observational study. Pharmacoepidemiol Drug Saf 21(9):911-919. https://doi.org/10.1002/pds.2268

54. Ljungman C, Kahan T, Schioler L, Hjerpe P, Hasselstrom J, Wettermark B, Bostrom KB, Manhem K (2014) Gender differences in antihypertensive drug treatment: results from the Swedish primary care cardiovascular database (SPCCD). J Am Soc Hypertens 8(12):882-890. https://doi.org/10.1016/j.jash.2014.08.015

55. Yoon SS, Carroll MD, Fryar CD (2015) Hypertension prevalence and control among adults: United States, 2011-2014. NCHS Data Brief 220:1-8

56. Bjorck F, Kadhim H, Sjalander A (2019) Predictors for INR-control in a well-managed warfarin treatment setting. J Thromb Thrombolysis 47(2):227-232. https://doi.org/10.1007/s11239018-1765-4

57. Wieloch M, Sjalander A, Frykman V, Rosenqvist M, Eriksson N, Svensson PJ (2011) Anticoagulation control in Sweden: reports of time in therapeutic range, major bleeding, and thrombo-embolic complications from the national quality registry AuriculA. Eur Heart J 32(18):2282-2289. https://doi.org/10.1093/eurheartj/ ehr134

58. Rose AJ, Ozonoff A, Grant RW, Henault LE, Hylek EM (2009) Epidemiology of subtherapeutic anticoagulation in the United States. Circ Cardiovasc Qual Outcomes 2(6):591-597. https://doi. org/10.1161/CIRCOUTCOMES.109.862763

Publisher's note Springer Nature remains neutral with regard to jurisdictional claims in published maps and institutional affiliations. 